Journal of Research in Interprofessional

Practice and

Education

Vol. 1.3

December, 2010

\title{
A Qualitative Study of Workplace Factors Influencing Expertise in the Delivery of Children's Education and Mental Health Services
}

\author{
Gillian King, PhD; Jacqueline Specht, PhD; Doreen Bartlett, PhD; \\ Michelle Servais, MEd; Patricia Petersen, CBC; Heather Brown, MEd; \\ Gabrielle Young, MEd; Shannon Stewart, PhD
}

\begin{abstract}
Background: Interest in professional expertise is growing. Interactional and developmental perspectives are being adopted to understand the nature of expertise and the environmental factors that influence its development. This article provides qualitative information about the workplace factors and experiences considered important by individuals providing education or mental health services to children, with one group working within an interprofessional team approach (service providers) and the other working in a discipline-specific manner (teachers).

Methods and Findings: Two focus groups were held: one involving 5 elementary or secondary school teachers and principals, and one involving 9 therapists who provide specialized children's mental health services. Information arising in these group sessions was used to develop themes reflecting key elements discussed; the themes were then contrasted to infer differences between the two groups. The findings point to the importance of establishing a collaborative, learning-oriented workplace culture, including opportunities for varied work experiences, peer interaction and dialogue, and feedback.

Conclusions: Implications include adopting relationship-oriented and collaborative service delivery models and ensuring that workplace settings encourage natural learning opportunities involving interaction, dialogue, and feedback, as well as meaningful professional development experiences of value to participants.
\end{abstract}

Keywords: Expertise; Service delivery; Children; Workplace; Development

\section{Introduction}

There is growing interest in understanding how to enhance the knowledge and skills of the professional groups who provide children's education and healthrelated services. The level of expertise of the teacher or mental health professional (i.e., occupational, physical, and behavioural therapist) is essential to children's educational or life outcomes. Teaching quality is widely considered to influence student achievement and success in the classroom [1]. Similarly, service providers' expertise is considered to play an important role in bringing about positive outcomes for children with physical or emotional difficulties [2]. Expertise in managing the clinical encounter or the classroom experience is at the heart of service delivery: It is where the qualities, skills, and procedural knowledge of effective professionals enable them to optimize service delivery or the classroom learning experience. This expertise is fundamental to the delivery of optimal clinical services [3] and to evidencebased practice [4]. 
266

Workplace Factors in Expertise Development

King, Specht, Bartlett, Servais, Petersen, Brown, Young, \& Stewart

Journal of Research in Interprofessional Practice and Education

Vol. 1.3

December, 2010
To date, our program of research on expertise development has focused on therapists delivering children's heath and mental health services [5-7]. Recently, we have become interested in similarities and differences in how teachers and service providers practice, and the role played by workplace factors in their professional growth. Because little research has investigated the role of workplace factors in the development of expertise, we conducted a qualitative study designed to capture teachers' and service providers' perceptions of the major factors influencing the development of their knowledge, skills, and approaches to practice. Themes related to workplace factors emerging from this study were compared for the school and treatment centre settings, allowing us to examine the role of interprofessional practice in contributing to experiences of personal growth in the workplace. Teachers typically practice in a discipline-specific manner whereas many children's mental health service providers now work in collaborative interprofessional teams based on interdisciplinary and transdisciplinary models. In a transdisciplinary model, practitioners engage in joint assessments, role expansion, and role release [8]. In an interdisciplinary model, practitioners work together closely and collaboratively but do not engage in arena assessments or role release [9].

In the following sections, we discuss the theoretical basis for the present research and the importance of examining the role played by workplace factors in the development of expertise. We then discuss what is known about the role of workplace factors in the delivery of children's education and health services.

\section{Theoretical basis for the research}

The research was guided by a transdisciplinary, developmental perspective [10] and an interactional model [11]. In this model, expertise is considered to require certain capacities and motivation on the part of the individual, particular types of experiences, and an environmental context that provides supports and opportunities for optimal experiences and the processing of experience [11]. This socialcognitive approach encompasses both socio-cultural and cognitive aspects of learning [12].

Based on a review of the literature in the fields of education, physical therapy, occupational therapy, medicine, nursing, and counseling and psychotherapy, we have defined expertise as the ability to show appropriate, exceptional, or adaptive performance or behaviour in response to a situation containing a degree of unpredictability or uncertainty [13]. This ability is based on a set of content, procedural, and self-knowledge [14,15]; personal qualities and characteristics (i.e., attitudes, values, traits) [16]; and skills and abilities (e.g., technical, interpersonal, self-regulation, meta-cognitive skills) $[17,18]$. The literature clearly indicates that there are many commonalities in the ways that experts in different human service delivery professions approach their clients and practice [19]. Similar to the healthcare literature, the education literature indicates that expertise in teaching is multifaceted and involves content and procedural knowledge, skills and abilities, and a student-centred approach [20]. 
267

Workplace Factors in Expertise Development

King, Specht, Bartlett, Servais, Petersen, Brown, Young, \& Stewart

Journal of Research in Interprofessional Practice and Education

Vol. 1.3

December, 2010
Importance of examining the role of workplace influences on expertise development

The literature on the development of expertise in service delivery has typically paid attention to personal factors that drive development, such as motivation and openness to experience [21,22], rather than interpersonal or workplace factors [7]. Extensive and challenging experience is considered necessary for the development of expertise [23,24], but relatively little is known about the types of environmental factors that maximize the likelihood of these types of experiences. Articles on expertise development typically emphasize learning on the individual level, thereby minimizing the appreciable impact that situation and context can have on the development of expertise. There is increasing acknowledgement, however, of the importance of workplace culture and climate on the quality of practitioners' work with clients $[25,26]$ and also on teachers' learning in the workplace [27,28].

Particular types of experiences and an environmental context that provides supports, resources, and opportunities for optimal experiences and the processing of experience are considered to be important for both clinical service providers and teachers. For example, the literature on learning in health and social care indicates the importance of a supportive, no-blame culture [29], learning supports and opportunities [30], and informal, situated learning arising through experience [31]. Similarly, the literature on teacher development indicates the importance of a supportive and collaborative school culture $[27,32]$ and informal learning in the workplace [28]. There is also a separate literature on workplace learning and human resource development, which recognizes the importance of an appropriate learning environment. However, there is little empirical evidence regarding the precise nature of an effective learning climate [12].

In the following section, we consider what is known about the role of workplace factors in the delivery of children's education and health services.

\section{The role of workplace factors in the delivery of children's} education and health services

With respect to the school setting, articles have discussed the importance of a workplace culture that provides opportunities for learning and interaction [27,33], encourages reflection [32], sets a climate that encourages exploration and development [34], and facilitates evidence-based or research-based practice in the classroom [35]. Teacher educators have discussed barriers to innovative teaching practices, indicating that school norms and culture have a strong influence on the beliefs and practices of new teachers, due to fear of censure and worry for their jobs [34]. Administrators play an important role in setting a climate that either supports teacher development or one that encourages blind adherence to standardized practices, is not evidence-based, and does not further student learning [34,36].

In the clinical setting, workplace culture plays an important role in the development of therapist expertise. Various workplace strategies have been proposed to create opportunities for learning, including the allocation of work and the structuring of work relationships [30]. According to King [11], there are three main types of 
268

Workplace Factors in Expertise Development

King, Specht, Bartlett, Servais, Petersen, Brown, Young, \& Stewart

Journal of Research in Interprofessional Practice and Education

Vol. 1.3

December, 2010 environmental-level strategies: caseload experiences, structured formal opportunities, and formal apprenticeship models. Caseload experiences include opportunities to work with clients with complex service needs [7]; to work with the same population for extended periods [37]; and to co-deliver services through multidisciplinary, interdisciplinary, and transdisciplinary team models [38]. Structured formal opportunities include opportunities for mentorship roles, feedback, dialogue, reflection, and group instruction [11]. Various types of formal apprenticeship models have been described in the literature, including cognitive apprenticeship [39] and guided participation in communities of practice [40]. These models have a number of common features, including explication of approaches and strategies, demonstration of skills, provision of immediate feedback, dialogue to ensure understanding, and provision of opportunities for practice to improve skills and performance.

However, few articles have addressed teachers' or service providers' perceptions of the factors that enhance or constrain expertise development in the organizations in which they work. The bodies of literature on teacher and service provider expertise, professional development, and interprofessional education and care are seldom integrated. Consequently, little is known about commonalities and differences in the "lived experiences" of those who provide educational versus therapeutic services to children. There may be differences in aspects of workplace settings (i.e., school versus treatment centre) that are important to know for practical purposes. Of most interest, such a comparison may reveal factors associated with the importance of team approaches to children's service delivery because teachers practice in a discipline-specific manner whereas children's mental health service providers typically practice interprofessionally.

\section{Study objective}

The aim was to examine workplace factors that enhance or constrain the development of expertise in children's service delivery. Focus groups were held to obtain information about commonalities and differences in workplace factors in two settings concerned with the well-being of children-education and mental health services. The intent of the focus groups was to obtain preliminary, practice-relevant information about the nature of the resources, supports, and opportunities that foster expertise development in the workplace, and to determine which factors were perceived to be most important by the two professional groups (teachers and service providers). The aim was not to examine ways in which the two groups work together, but rather to compare the nature of the most important workplace factors for a group working in an interprofessional manner (the service providers) with those of a group working in a discipline-specific manner (the teachers).

\section{Methods}

\section{Participants}

Participants were recruited through school boards and a regional mental health service agency in London, Ontario, Canada. Approval was received from the 
269

Workplace Factors in Expertise Development

King, Specht, Bartlett, Servais, Petersen, Brown, Young, \& Stewart

Journal of Research in Interprofessional Practice and Education

Vol. 1.3

December, 2010
University of Western Ontario's Ethical Review Board. An invitation flyer was sent to selected members of the recruiting organizations, inviting them to attend a focus group on the factors that help to foster professional expertise.

A total of 14 participants took part. Five participants ( 3 women, 2 men; 2 special education teachers, 1 teacher, 2 principals) were recruited from local school boards and took part in a Teacher Focus Group held at the University of Western Ontario. Nine participants (all women; 2 speech-language pathologists, 3 behavioural consultants, 1 occupational therapist, 1 social worker, 1 psychologist, and 1 physical therapist) were recruited from the mental health service agency and took part in a Service Provider Focus Group held at the agency.

\section{Procedure}

Teachers and service providers took part in separate focus groups to facilitate focused discussion of issues related to expertise in their profession. Two semi-structured focus groups were facilitated by two study investigators, each lasting approximately 90 minutes. The sessions were digitally recorded and professionally transcribed, with all identifying information removed.

Because the focus groups were designed to capture information about factors influencing professional development in general, we did not initially prompt for both personal and workplace or system-related factors. Instead, our interest was to see the nature of the factors that emerged spontaneously in the discussions. Consequently, our interview questions were designed to be broad in nature. They included the following: What do you think of when you hear the term "expertise?" How do you see expertise relating to outcomes for children in your profession? What types of experiences and ways of thinking are most highly associated with major shifts in expertise? What experiences have most influenced your professional growth?

\section{Qualitative approach and analysis}

Qualitative research provides rich information about a topic, is suited to in-depth exploration of complex issues, recognizes the influence of context, and focuses on the meaning of phenomena [41,42]. Consequently, a qualitative approach was ideally suited to exploring professionals' understanding of expertise and the role of workplace experiences in developing skills and knowledge.

We adopted a phenomenological approach, a form of inquiry that describes the meaning of individuals' lived experiences with respect to a concept or a phenomenon [43]. In a phenomenological study, themes are experiential components, which are integrated into a narrative depiction of a multifaceted phenomenon [44]. In the present case, the phenomenon of interest was perceptions of salient factors and experiences influencing the development of expertise or professional growth. We also compared the teachers' and service providers' perceptions of these factors. This reflects a higher level type of phenomenological approach, one that portrays how experience varies depending on individuality and context [44].

All investigators independently reviewed the transcripts and noted emerging themes and codes as part of an "open coding" approach. The team consisted of indi- 
270

Workplace Factors in Expertise Development

King, Specht, Bartlett, Servais, Petersen, Brown, Young, \& Stewart

Journal of Research in Interprofessional Practice and Education

Vol. 1.3

December, 2010 viduals with various professional backgrounds (social, developmental, and clinical psychology; education; physical therapy; behaviour therapy). As a group, we then identified key concepts, clustered these into themes, and revisited themes to further refine them [42]. Connections were made between common themes to form superordinate themes. The transcripts of teachers and service providers were then compared with respect to these super-ordinate themes. Agreement was reached with respect to the themes reported here.

\section{Results}

Four types of workplace factors were discussed by participants (presented in order of importance, based on the researchers' judgment of the degree to which each factor was stressed in the group discussions). These factors were: a) culture and climate of the workplace, b) isolation versus dialogue among fellow practitioners, c) opportunities for feedback, and d) formal education and training. These factors represented dimensions of workplace experiences that either enhanced or impeded expertise development, depending on their nature and degree of presence or absence. Commonalities and differences were found in the comments and observations of members of the two focus groups concerning their workplace experiences. The teachers and service providers primarily differed in whether their major focus was on supports or barriers. Generally speaking, the teachers discussed feelings of isolation in their profession, whereas the service providers talked about teamwork, collaboration, and communities of practice. The following sections contain quotes organized by these workplace factors, with the themes they represent compared for the teachers and service providers.

\section{Culture and climate of the workplace setting}

An organization's culture refers to its underlying assumptions, shared values, and behavioural expectations, whereas organizational climate refers to people's perceptions of working relationships or the workplace ambiance [45]. Participants discussed culture and climate in terms of whether the setting was supportive and learning-oriented, or not.

\section{Teachers}

The teachers questioned whether school settings were conducive to the development of expertise. They felt that both new and highly experienced teachers faced difficulties in applying their expertise to achieve the desired outcome, namely students' learning.

I think there are the first-year teachers that know what they need to do, the same way there are 20-year teachers that know what they need to do. But they're being told "Forget about that, do this." And so, I don't know if all the teachers are actually being able to apply their expertise ... because it's a job ... it's not a mastery model for education.

At times, the teachers felt constrained by top-down ministry initiatives. However, they worked around ministry constraints and took risks so that children could be successful learners. 


\section{JRIPE}

271

Workplace Factors in Expertise Development

King, Specht, Bartlett, Servais, Petersen, Brown, Young, \& Stewart

Journal of Research in Interprofessional Practice and Education

Vol. 1.3

December, 2010

\section{Journal of Research in Interprofessional Practice and Education}

That has happened for many, many different initiatives, and you can kind of play the political game.... The principal's in, so you know you're supposed to be doing this ... but then ... when he or she is gone ...

If they're being mandated by the board or the ministry "Thou shalt do this," you can take that but massage it to fit the child, and still get your outcomes, your successful outcomes.

The teachers discussed how the Ontario Ministry of Education had implemented a New Teacher Induction Program designed to create networks of people who provide resources and supports to one another. There appeared to be a general understanding of the teaching system as non-supportive of new teachers.

[This program] was conceived in clear recognition of that fact that [Ministry officials] were unhappy with the fact that they were losing so many teachers in the first five years... It's a Ministry initiative to try and stem that.... I remember in a bit of academic reading I did that the teaching profession loves to eat its young.

\section{Service providers}

In contrast, the service providers experienced a collaborative, relationship-oriented work culture.

I'm probably the newest person to [workplace] around the table, and I would say...one thing that's unique ... [and] facilitates that team feel and collaboration is low turnover... It's relationship first.... It sort of feels like there actually are so many interconnections and histories that ... when you come in you become part of that collaboration because ... it's just kind of part of the culture.

The service providers also talked about the role organizational leaders played in defining what matters in the workplace. They paid attention to, and became good at, what was currently valued and being "counted."

And the other thing I found ... it's whatever [they] tend to measure, you get really good at.... You spend more time on it, you get better at it... [For example,] it could be the waiting lists. As soon as they start putting ... the spotlight on waiting lists, then you get better at managing your waiting list.

Organizational leaders provided support and inspiration for service providers, affecting the degree to which they were willing to deviate from guidelines to meet client needs.

There are times when you can be really inspired by your leadership... [If you feel] supported going outside the box or ... trying something new... That can really help you ... because [with] so many clients that we work with, it just doesn't ... go nice and neat and tidy in eight weeks.... You have to be able to ... recognize that 


\section{JRIPE}

272

Workplace Factors in Expertise Development

King, Specht, Bartlett, Servais, Petersen, Brown, Young, \& Stewart just about every kid you work with is the exception to some rule or another.

The service providers felt there was an organizational focus on learning particular discipline-related techniques, rather than on the "soft skills" required to work collaboratively. Skills in listening, rapport development, and goal negotiation were taken for granted.

Even though we've acknowledged that [listening skills] are very important, they seem to be very soft.... If I can go and learn about [a] specific aspect about kids and behaviour and anxiety [versus] something that's about assessing whether or not I'm a good listener[the latter] is just not going to make the cut.

\section{Isolation versus dialogue}

This was a major theme, clearly related to the culture of the workplace.

\section{Teachers}

In contrast to the service providers, the teachers felt a sense of isolation.

[It is important to] have that opportunity to come together as peers - to dialogue, to reflect, and to guide each other. And I think there is a lot of wisdom out there, but we're all in our own little cubicle, so I don't know what you're doing.... Because I don't have time to communicate with you, or we don't have time to sit and reflect on it, I am not going to grow in that area. And I think that is hugely missing in teaching.

Novice teachers and those on limited-term contracts, especially, experienced a lack of support in the school setting.

Once they hire you with a contract, you're one of the chosen few ... but as long as you're playing the [limited-term contract] game, no one gives a damn. You're out there in the wilderness... You get a little bit of assistance [but] there's no investment in you.... So, in terms of developing your "expertise," you have to either sink or swim very fast.

One teacher talked about an experience in which he had the opportunity to observe an experienced teacher and how this "incursion" into another teacher's classroom was atypical.

The structure and tradition of teaching is that it's considered to be a very autonomous exercise, and these incursions, so to speak, on other people's classrooms are often viewed as that.... I remember as a high school tech teacher, I went to a local elementary school to do a tech unit with a grade 5 class.... I was with this woman who was like 15 minutes from retirement [laughter]. I learned more than she or the kids did ... just watching how she managed a group of kids in

December, 2010 


\section{JRIPE}

273

Workplace Factors in Expertise Development

King, Specht, Bartlett, Servais, Petersen, Brown, Young, \& Stewart a classroom and seeing the kind of expertise that she had. So that's a barrier because the board had to pay big bucks to free me, and I had to be willing. And she had to be receptive ... and what it all comes down to a lot of times is time, which translates into money, and the willingness of co-professionals to share in that way.... I'm not sure why we are so protective of that classroom autonomy.

\section{Service providers}

Although both groups spoke about the importance of dialogue, opportunities for peer networking, dialogue, and support were much greater in the service provider setting, which employed interdisciplinary or transdisciplinary models to deliver children's mental health services. Team discussion was particularly important for the service providers, as it allowed them to see the big picture and brainstorm effectively.

If you do have a conference or ... rounds on the residential unit ... when a kid is just struggling, struggling, struggling, and you're all sitting around looking at each other like, "Wow, can you believe that happened last night?" But you kind of pick up the pieces and you have a discussion, and you say, "Well, what if we try this, and what if we try that?"

The service providers felt comfortable in approaching colleagues and in engaging in accidental brainstorming, often in hallway conversations.

Something I appreciate is being able to walk into somebody's office and say, "What do you think about this?" Or, "Have you ever worked with somebody like that?" That's just priceless.

When you have clients booked back to back to back, there's sometimes no time to do that reflection. I think we make [time] though.... We make those opportunities.... I think the culture here is very, very interdependent, and we have to be.

In the hospitals things are much more regimented.... It doesn't allow for the same [kind of learning] that happens here-just the informality and the interdisciplinary kind of dialogue.... It makes a huge difference.

\section{Opportunities for feedback}

Each setting struggled with providing opportunities for feedback from peers and clients, whether students or families.

Journal of Research in Interprofessional Practice and Education

Vol. 1.3

December, 2010

\section{Teachers}

Teachers in Ontario are not encouraged, due to union issues, to evaluate or provide formal feedback to one another. "The federations have a real problem with anything that smacks of ...peer evaluation." Nonetheless, the teachers acknowledged the importance of asking others for feedback, particularly the client. 


\section{JRIPE}

274

Workplace Factors in Expertise Development

King, Specht, Bartlett, Servais, Petersen, Brown, Young, \& Stewart

Journal of Research in Interprofessional Practice and Education

Vol. 1.3

December, 2010

\section{Journal of Research in Interprofessional Practice and Education}

One of the things that came out of [the New Teacher Induction Program was that] ... they encourage us to go back to our students ... and ask them very simply...."What should I continue to do, what should I stop doing, what should I have started to do, to [be] more successful?" As the teacher out there on the practicum, you had some good, some sobering feedback [laughter].... That's something that we have to be reminded of ... are you serving your client?

\section{Service providers}

The service providers felt it was often difficult to provide honest feedback to peers without jeopardizing relationships.

We've been talking a lot today about expertise in the context of work with our clients, but so much of what we do is how we have expertise within a context of teams.... And that can be a bit intimidating when you start assessing your colleagues and the dynamics around that ... teams are so ... fragile, you know?

In contrast to the teachers, the service providers paid more attention to mechanisms by which to obtain feedback. They discussed the relative value of feedback from peers and families and questioned the validity of self-assessments.

I think your best measure is your client and your client families.... We get feedback from difficult parents that makes us rethink what we do or what we might have done differently.... Peer reviews, I think they're fine personally, though I think there's some peers that ... I wouldn't necessarily respect their review.

With listening skills and self-awareness and things like that, what concerns me is ... I think there's a literature [that] the people that rate themselves the highest on those things actually don't match up with other people's observations [laughter].... Some people are really hard on themselves and say "I need to improve in all areas," and other people by nature are very, very confident and perhaps shouldn't be, so it's hard to create a tool that captures ... whether perception meets reality.

\section{Formal education and training}

The settings differed in the number of opportunities they provided for professional development (PD).

\section{Teachers}

The teachers indicated that PD days were often viewed as a waste of time. Different PD days, et cetera, where the goal is to develop expertise in a certain area-there just seems to be a lot of cynicism about [them]. "This is a waste of my time, I can't learn anything from this" [and] "There are places I would rather be." So ... you've got to have a staff 
275

Workplace Factors in Expertise Development

King, Specht, Bartlett, Servais, Petersen, Brown, Young, \& Stewart
Journal of Research in Interprofessional Practice and Education

Vol. 1.3

December, 2010 that's going to buy into it.... You don't [want to] feel that someone is assuming you need this, and they're imposing this on you-[rather] you're all part of it.

\section{Service providers}

The service providers talked about practice-based evidence (i.e., evidence derived from systematically investigating practice) and new training that helped them to rethink their ways of doing things. Training was mandatory, due to professional college requirements, and many PD opportunities were provided.

When I first started with the program, I came with my own knowledge base and my own set of skills, and was quite astonished at just how much I actually did need to learn when I got sent for ongoing education.... If it looked or smelled like it was a PDD [pervasive developmental disorder] thing, I went to it.... That was something that I absolutely did appreciate.... That was very helpful, [something] that I wouldn't have been afforded outside of this position.

That's what I've noticed about [the workplace setting] - for our college, we have to keep track of our continuing education, and we're supposed to have 45 hours over a three-year cycle. Well, I've almost hit those 45 hours just by being at [setting] because there's so much opportunity here for development. No one's ever really said no to me about taking anything I wanted to take.

\section{Discussion}

The findings of this preliminary focus group study indicate the nature of the workplace factors that a group of teachers and a group of mental health service providers considered to be most important in developing their expertise. The findings provide a unique cross-sectoral view of workplace factors considered to influence professional growth in children's service providers in two settings-schools in a mediumsized city in Southwestern Ontario, Canada and a mental health agency in the same city. The findings highlight the importance of a collaborative, learning-oriented workplace culture that provides opportunities for varied work experiences, peer interaction and dialogue, and feedback. The teachers and mental health service providers reported quite different experiences in these four areas. Since these groups practice in a discipline-specific and interprofessional team manner, respectively, the findings provide intriguing preliminary information about the role of an interprofessional workplace context in enhancing professional development.

The findings indicated that teachers felt unable to apply their expertise due to constrained roles. They also felt isolated. Teachers on limited-term appointments, in particular, were considered to experience a lack of support. As a group, the teachers felt that professional development experiences were often a waste of time. In contrast, the service providers experienced a collaborative, relationship-oriented workplace. They reported many opportunities for peer dialogue and support, and they expressed positive attitudes toward the professional development 
276

Workplace Factors in Expertise Development

King, Specht, Bartlett, Servais, Petersen, Brown, Young, \& Stewart

Journal of Research in Interprofessional Practice and Education

Vol. 1.3

December, 2010 opportunities open to them. Both groups experienced a lack of opportunity to obtain feedback on their performance from clients (or students), colleagues, and supervisors.

We posit that the two very different experiences of the teachers and service providers were tied to the manner in which they worked. Teaching is clearly an autonomous activity [28]. For teachers, the set up of the school day and their different roles and responsibilities can provide limited opportunities and time for exploration, dialogue, and reflection [27], creating the sense of professional isolation reported in the present study. In contrast, the service providers indicated that they practiced interprofessionally and recognized the importance of organizational culture, cross-disciplinary interaction, and workplace relationships. The service providers were known to work in collaborative interprofessional teams based on interdisciplinary and transdisciplinary models, as shown in a previous publication involving service providers from this regional mental health agency [8].

Overall, the findings indicate that workplace culture and climate play a major role in limiting practitioners' success or enhancing their practice by providing guidance, support, and context-relevant opportunities for professional learning. The findings point to the overarching role played by workplace environments in setting norms and opportunities for ongoing dialogue and learning through interaction with peers, thus reflecting the literature on relationship-based practice and situated learning through communities of practice $[40,46]$. The findings also support the view that ongoing development of skills and knowledge in the workplace is dependent on safe, supportive learning environments; opportunities for reflection, job challenge, and formal learning; and informal learning arising through experience and interaction with others $[12,30,47]$. Overall, the study makes a unique contribution to the literature by suggesting the importance of work environments that are collaborative, individualized, and enabling by virtue of the informal, ongoing, and naturally occurring opportunities they provide for supportive, growth-promoting sharing of ideas and information.

In the following sections, we consider links between the four major factors discussed in the focus groups with the literature on workplace culture and with the literature on the creation of workplace opportunities for expertise development. We then consider the role of service delivery models in creating a supportive, learningoriented workplace culture and in providing such opportunities for professional growth.

\section{The role of workplace culture}

Organizational culture can play either a positive or a negative role in providing conditions for different kinds of learning experiences, as well as kinds and levels of reflection on the self and practice [32]. There were clear differences in the workplace environments of the teachers and service providers in the present study. Expertise development was not supported by the values and practices of the teaching profession, which included a culture of professional autonomy (limiting oppor- 
277

Workplace Factors in Expertise Development

King, Specht, Bartlett, Servais, Petersen, Brown, Young, \& Stewart

Journal of Research in Interprofessional Practice and Education

Vol. 1.3

December, 2010 tunities to observe and interact with other teachers) and union rules discouraging peer assessment (limiting feedback).

In contrast, the mental health setting provided a collaborative, learning-oriented work environment that fostered practitioner development. The setting provided a much greater degree of access to other professionals with greater and different knowledge and skills. It also provided an appreciable number of opportunities for specialized formal education and training around the diagnoses of the children, who had severe mental health difficulties. The interdisciplinary/transdisciplinary models adopted in the various programs allowed service providers to establish "communities of practice" (a term used by participants), which appeared to naturally foster mentoring, dialogue, and the provision of feedback. The present findings suggest that benefits will accrue from the deliberate design of a workplace environment that fosters a culture of learning [48] and interprofessional teamwork [49]. As shown in the present findings, the leadership context of the workplace directs the focus of attention and defines what matters to employees. For example, service providers talked about the role of organizational leaders in establishing what behaviours are valued in the workplace.

\section{Naturally occurring, situated opportunities for expertise development}

The findings indicated the need to ensure opportunities for varied work experiences, interaction and dialogue with peers, and multiple sources of constructively delivered feedback. Each is discussed in turn.

First, there is evidence that opportunities for varied work experiences are required for professional growth. In clinical practice, exposure to many experiences leads to adaptability in problem solving and individualized strategy selection [7]. Service providers in the present study indicated the importance of sometimes deviating from standard practice in order to meet unique client needs, reflecting the view that customization of service provision is related to intervention effectiveness and client satisfaction with services [50]. Experts provide services in an individualized manner, using enabling and customizing strategies to engage with clients [6].

Second, the findings indicate that a major way that individuals learn is through dialogue and collaboration with others engaged in similar enterprises. Similarly, the literature indicates that skills and awareness are developed through collaboration among team members [51], where there is mutual exploration of issues and joint decision making about best courses of action. For effective collaborative practice, the literature indicates that there needs to be sufficient time for staff members to interact and develop interpersonal relationships [52,53]. In a relationship-based culture, the mutual valuing and respect among co-workers makes it natural to collaborate [26].

Third, the findings indicate that constructive feedback from multiple sources, including supervisors, peers, and clients/students, is highly desirable for professional growth. As indicated by the mental health service providers, feedback is extremely important for the development of professional expertise [54]. Unfortunately, the professional autonomy of teachers in the present study impeded 
278

Workplace Factors in Expertise Development

King, Specht, Bartlett, Servais, Petersen, Brown, Young, \& Stewart

Journal of Research in Interprofessional Practice and Education

Vol. 1.3

December, 2010 giving and receiving feedback. Because there are challenges in formalizing feedback processes, informal opportunities that encourage dialogue about strategies and outcomes may be preferable. Informal opportunities include those where feedback is reciprocal and incidental, such as when a colleague indicates what she herself would do differently or when a new strategy is observed and discussed.

When giving and receiving feedback is a normal part of the way of working, it may be easier for practitioners to accept and be motivated by others' comments and observations. Unfortunately, many professional tasks and roles often fail to provide the immediate, consistent, and supportively given feedback necessary for improvement [55]. For example, therapists working independently in community-based roles and teachers not engaged in team teaching have limited opportunities to receive feedback from knowledgeable colleagues.

In addition to feedback given explicitly or obtained indirectly, feedback can be self-generated through the use of self-assessment tools. Although there are limits to the utility of self-assessment measures [29], measures providing scores that can be compared with others or over time may be very useful. Experts may benefit more from these tools than novices, perhaps because they are more predisposed toward self-reflection; alternatively, novices may benefit more from the guidance and insight provided by these tools [11].

Both teachers and service providers in the present study were reluctant to provide feedback to peers. However, this may be due to anxieties inherent in a more formal observation and feedback process [56], where there are implications for the other person's employment or status in an organization. Feedback given incidentally in the context of dialogue may be the type of immediate and tailored feedback that encourages skill development-positive behaviours can be supported and more effective approaches can be suggested. The person is in control over whether or not to use the suggestions and feels supported and empowered rather than criticized because the focus is on their behaviour rather than on them as a person.

\section{The importance of service delivery models}

Service delivery models provide vision and direction for workplace culture and ways of operating. Participants in the present study used the terms collaborative practice, relationship-based practice, and community of practice interchangeably. However, it should be noted that these are distinct concepts in the literature. Although all three notions concern interaction among groups of peers engaged in similar tasks and activities in the workplace, they come from different theoretical perspectives and literatures, stressing some aspects of learning or types of engagement more than others. For example, a community of practice is a model of learning based on a distinctive view of co-constructed knowledge. This model focuses on how practitioners learn, namely by mutual engagement in common activities [40].

The present findings indicate the importance of relationship-oriented and collaborative service delivery models to practitioners' day-to-day work experiences and professional growth. These models are receiving increased attention in the edu- 
279

Workplace Factors in Expertise Development

King, Specht, Bartlett, Servais, Petersen, Brown, Young, \& Stewart

Journal of Research in Interprofessional Practice and Education

Vol. 1.3

December, 2010 cation and healthcare literature. The findings can be considered to reflect the importance of both types of models.

In a relationship-oriented model of practitioner development, learning and selfdevelopment are considered to occur through dynamic interaction with other people, including working with others, talking about work, and observing others [2,57]. Relationship-oriented models of service delivery indicate that organizations can facilitate practitioner growth by providing enabling experiences tailored to their levels of experience $[2,58]$. For example, clinical managers and school principals can use three theoretically based strategies to facilitate workplace learning: supporting practitioners to have personal experiences that develop skills and knowledge (e.g., observing and receiving feedback from others), providing supports and resources (e.g., assessment tools and practice frameworks, mentoring programs), and ensuring the availability of workplace opportunities (e.g., caseload/classroom experiences, opportunities for dialogue and reflection) [11,58,59]. Thus, schools and service organizations can support workplace learning by encouraging innovation and exploration and by promoting working practices that facilitate good relationships and reflective interactions among staff members [60].

A second type of model is a collaborative interprofessional model, which includes interdisciplinary/transdisciplinary models and collaborative apprenticeship models. One of the major presumed benefits of these models is that they foster skill development. For example, a transdisciplinary approach is considered to provide opportunities and supports that enhance therapists' knowledge and skills and foster the collaborative mindset needed to work effectively with others [61,62]. In a collaborative apprenticeship model, professional learning is envisioned as a social enterprise in which peers serve as models and coaches and in which there is reliance on the expertise and support of others [27]. Articles have discussed the importance of collaborative apprenticeship and peer coaching in encouraging professional development and research-based teaching practices within school settings [e.g., 56].

These models are "ideal types." They are conceptual models based on various theoretical perspectives and are supported by a limited number of empirical studies [59]. The present findings suggest the importance of setting the conditions for the ways of operating described by the models, namely supportive relationships, individualized professional development experiences, coaching/mentoring, and collaborative teamwork. Research is needed to identify the most useful of these practices.

\section{Study limitations}

The study limitations stem from its qualitative nature. Because only two focus groups were involved, there are issues concerning the reproducibility of the results. The findings concerning isolation in the teaching profession may be specific to the individuals or workplace settings involved-elementary and secondary schools in the southwestern area of Ontario, Canada. However, classroom autonomy, policies that restrict classroom observation, and a sense of isolation are common experiences of teachers $[27,28]$. Similarly, the service provider setting may be unique in its collaborative, collegial nature, but it shares many of the characteristics of well-func- 
280

Workplace Factors in Expertise Development

King, Specht, Bartlett, Servais, Petersen, Brown, Young, \& Stewart

Journal of Research in Interprofessional Practice and Education

Vol. 1.3

December, 2010 tioning teams in supportive environments. Another study limitation is not asking study participants to verify the study themes that emerged from the qualitative analysis.

\section{Research implications}

First, the present findings need to be replicated using greater breadth and depth of sampling and data collection. Future research would benefit from including teachers and mental health service providers from other contexts or locations. Second, greater exploration is warranted of the utility of service delivery models exemplifying the supportive workplace characteristics identified in the present study. Third, future research could profitably examine the detailed nature of the main workplace factors identified here-varied work experiences, peer interaction and dialogue, and feedback. Quantitative studies of each type of factor could be undertaken, comparing and contrasting different types of workplace settings to determine the relative value of these factors in various types of children's service delivery organizations (schools, mental health service organizations, pediatric rehabilitation service organizations, children's hospitals).

\section{Implications for practice}

To ensure high quality children's services, schools and clinical organizations must strive to meet practitioners' learning needs. This section considers the implications of the findings for models of service delivery and the provision of learning opportunities in the workplace.

First, there are implications for service models adopted by organizations delivering children's services. Team approaches supporting "collaborative collegiality" [63] are required, such as relationship-oriented and collaborative practice models. Team teaching appears to be a useful way to reduce teacher isolation and transfer skills and strategies. Culturally speaking, the beliefs and practices of teachers-like any entrenched group-are extremely hard to influence [34]; however, they can be changed incrementally, with the ultimate vision of a supportive workplace environment kept in mind. The links between a positive, collaborative culture and higher staff satisfaction, lower turnover, and less burnout have been widely studied [26]. The mental health service agency in the present study experienced a low level of turnover, perhaps partly due to service providers' positive work relationships. In contrast, the teachers indicated that it was hard for the education system to retain its experts, which may be linked to the isolation experienced in teaching.

Second, there are implications for the provision of growth-enhancing workplace experiences. These workplace strategies cut across service delivery models. They include ensuring time and opportunity for reciprocal interaction and feedback, reflection, mentorship, and professional development experiences that are not specific to a child's condition or a particular classroom subject. Such opportunities allow practitioners to hear what other teachers are doing in their classrooms or what other service providers have gleaned from difficult client cases, and to discuss what worked or did not work, and why. Supportive, open-minded administrators 
281

Workplace Factors in Expertise Development

King, Specht, Bartlett, Servais, Petersen, Brown, Young, \& Stewart
Journal of Research in Interprofessional Practice and Education

Vol. 1.3

December, 2010 strive to meet the fundamental learning needs of practitioners [2,34]. In education, strategies that have been discussed include establishing teacher support programs involving a school-based staff developer/coach [56,64] and scheduling common student-free times for teachers who teach the same subjects or grade levels $[27,28]$.

In conclusion, the findings of this qualitative study on workplace factors influencing the development of expertise of teachers and mental health service professionals indicates the importance of understanding workplace dynamics and culture and suggests the importance of investing in the human capital of these service delivery enterprises [34]. Knowledge and skills need to be constantly developed and nurtured for positive outcomes for children-both their learning outcomes in school and their emotional well-being. Overall, the findings indicate the importance of workplace settings that encourage natural learning opportunities involving interaction, dialogue, and feedback, as well as meaningful professional development experiences of value to participants.

\section{Acknowledgements}

The authors would like to thank the Social Sciences and Humanities Research Council of Canada for their funding support.

\section{References}

1. Blanton, L.P., Sindelar, P.T, \& Correa, V.I. (2006). Models and measures of beginning teacher quality. The Journal of Special Education, 40(2), 115-27.

2. King, G. (2009). A relational goal-oriented model of optimal service delivery to children and families. Physical \& Occupational Therapy in Pediatrics, 29(4), 384-408.

3. King, G. (2007). Expertise in evidence-based clinical decision-making: Working effectively with families. Perspectives on Augmentative and Alternative Communication, 16(3), 2-7.

4. King, G., Batorowicz, B., \& Shepherd, T.A. (2008). Expertise in research-informed clinical decision making: Working effectively with families of children with little or no functional speech. Evidence-Based Communication Assessment and Intervention, 2(2), 106-16.

5. King, G., Bartlett, D.J., Currie, M., Gilpin, M., Baxter, D., Willoughby, C., et al. (2008). Measuring the expertise of pediatric rehabilitation therapists. International Journal of Disability, Development and Education, 55(1), 5-26.

6. King, G., Currie, M., Bartlett, D., Gilpin, M., Willoughby, C., Tucker, M.A., et al. (2007). The development of expertise in pediatric rehabilitation therapists: Changes in approach, self-knowledge, and use of enabling and customizing strategies. Developmental Neurorehabilitation, 10(3), 223-40.

7. King, G., Currie, M., Bartlett, D.J., Strachan, D., Tucker, M.A., \& Willoughby, C. (2008). The development of expertise in paediatric rehabilitation therapists: The roles of motivation, openness to experience, and types of caseload experience. Australian Occupational Therapy Journal, 55, 108-22.

8. King, G., Strachan, D., Tucker, M., Duwyn, B., Desserud, S., \& Shillington, M. (2009). The application of a transdisciplinary model for early intervention services. Infants \& Young Children, 22(3), 210-22.

9. Foley, G.M. (1990). Portrait of the arena evaluation: Assessment in the transdisciplinary approach. In E. Biggs \& D. Teti, (Eds.). Interdisciplinary assessment of infants: A guide for early intervention professionals (pp. 271-286). Baltimore, MD: Paul H. Brookes.

10. Lerner, R.M. Theories of human development: Contemporary perspectives. In R.M. Lerner RM, (Ed.), Handbook of child psychology, (5th ed), pp.1-24. New York: John Wiley \& Sons.

11. King, G. (2009). A framework of personal and environmental learning-based strategies to foster therapist expertise. Learning in Health and Social Care, 8(3), 185-99.

12. Clarke, N. (2005). Workplace learning environment and its relationship with learning outcomes in healthcare organizations. Human Resource Development International. 8(2), 185-205. 
282

Workplace Factors in Expertise Development

King, Specht, Bartlett, Servais, Petersen, Brown, Young, \& Stewart

Journal of Research in Interprofessional Practice and Education

Vol. 1.3

December, 2010
13. Dorner, D., \& Scholkopf, J. (1991). Controlling complex systems; or, expertise as “grandmother's know-how." In K.A. Ericsson \& J. Smith, (Eds.), Toward a general theory of expertise: Prospects and limits (pp. 218-239). New York: Cambridge University Press.

14. Goodyear, R.K. (1997). Psychological expertise and the role of individual differences: An exploration of issues. Educational Psychology Review, 9(3), 251-65.

15. Rogers, J.C., \& Holm, M.B. (1997). Diagnostic reasoning: The process of problem identification. In Christiansen CH, Baum CM, editors. Occupational therapy: Enabling function and well being (pp. 137-156). Thorofare, NJ: Slack.

16. Moore, T.G. (2004). Blazing new trails: Finding the most direct routes in early childhood intervention. 6th National Conference of Early Childhood Intervention, Australia. Melbourne, Australia.

17. Rivett, D., \& Higgs, J. (1995). Experience and expertise in clinical reasoning. New Zealand Journal of Physiotherapy, 23, 16-21.

18. Sternberg, R.J. (1999). Intelligence as developing expertise. Contemporary Educational Psychology, 24, 359-75.

19. Berliner, D.C. (2004). Describing the behavior and documenting the accomplishments of expert teachers. Bulletin of Science, Technology \& Society, 24, 200-212.

20. Smith, T.W., \& Strahan, D. (2004). Toward a prototype of expertise in teaching: A descriptive case study. Journal of Teacher Education, 55(4), 357-71.

21. Jennings, L., \& Skovholt, T.M. (1999). The cognitive, emotional, and relational characteristics of master therapists. Journal of Counseling Psychology, 46(1), 3-11.

22. Skovholt, T.M., Jennings, L., \& Mullenbach, M. (2004). Portrait of the master therapist: Developmental model of the highly functioning self. In T.M. Skovholt, \& L. Jennings (Eds.), Master therapists: Exploring expertise in therapy and counseling (pp. 125-146). Boston: Allyn \& Bacon.

23. Csikszentmihalyi, M., \& Rathunde, K. (1998). The development of the person: An experiential perspective on the ontogenesis of psychological complexity. In R.M. Lerner (Ed.), Handbook of child psychology Theoretical models of human development (5th ed), (pp. 635-84). New York: John Wiley \& Sons.

24. Biemiller, A., \& Meichenbaum, D. (1992). The nature and nurture of the self-directed learner. Educational Leadership, 50(2), 75-80.

25. Glisson, C. (2002). The organizational context of children's mental health services. Clinical Child and Family Psychology Review, 5(4), 233-53.

26. Safran, D,G., Miller, W., \& Beckman, H. (2006). Organizational dimensions of relationship-centered care theory, evidence, and practice. Journal of General Internal Medicine, 21, 9-15.

27. Glazer, E.M., \& Hannafin, M.J. (2006). The collaborative apprenticeship model: Situated professional development within school settings. Teaching and Teacher Education, 22(2), 179-93.

28. Lohman, M.C. (2005). Environmental inhibitors to informal learning in the workplace: A case study of public school teachers. Adult Education Quarterly, 50(2), 83-101.

29. Miller, P.A. (2008). Self-assessment: The disconnect between research and rhetoric. Physiotherapy Canada, 60, 117-24.

30. Eraut, M. (2006). Learning contexts. Learning in Health and Social Care, 5, 1-8.

31. Shakespeare, P. (2006). Editorial. Learning in Health and Social Care, 5(4), 169-80.

32. Day, C. (1993). Reflection: A necessary but not sufficient condition for professional development. British Educational Research Journal, 19(1), 83-93.

33. Dall'Alba, G., Sandberg, J. (2006). Unveiling professional development: A critical review of stage models. Review of Educational Research, 76(3), 383-412.

34. Newman, J.M. (1998). We can't get there from here: Critical issues in school reform. Phi Delta Kappan, 80(4), 288-94.

35. Klingner, J.K. (2004). The science of professional development. Journal of Learning Disabilities, 37, 248-55.

36. Klingner, J.K., Ahwee, S., Pilonieta, P., Menendez, R. (2003). Barriers and facilitators in scaling up research-based practices. Exceptional Children, 69(4), 411-29.

37. Rees, P.G., \& Hays, B.J. (1996). Fostering expertise in occupational health nursing: Levels of skill development. Journal of the American Association of Occupational Health Nursing, 44(2), 67-72.

38. Dyer, J.A. (2003). Multidisciplinary, interdisciplinary, and transdisciplinary educational models and nursing education. Nursing Education Perspectives, 24(4), 186-188.

39. Collins, A., Brown, J.S., \& Newman, S.E. (1989). Cognitive apprenticeship: Teaching the crafts of reading, writing, and mathematics. In L. B. Resnick (Ed.), Knowing, learning, and instruction (pp. 453-494). Hillsdale, NJ: Erlbaum. 
283

Workplace Factors in Expertise Development

King, Specht, Bartlett, Servais, Petersen, Brown, Young, \& Stewart

Journal of Research in Interprofessional Practice and Education

Vol. 1.3

December, 2010
40. Lave, J., \& Wenger, E. (1991). Situated learning: Legitimate peripheral participation. Cambridge: Cambridge University Press.

41. Wright, J.G., \& McKeever, P. (2000). Qualitative research: Its role in clinical research. Annals RCPSC, 33(5), 275-80.

42. Fiese, B.H., Bickham, N.L. (1998). Qualitative inquiry: An overview for pediatric psychology. Journal of Pediatric Psychology, 23(2), 79-86.

43. Creswell, J.W. (2007). Qualitative inquiry and research design, (2nd ed). Thousand Oaks, CA: Sage.

44. Kearney, M.H. (2001). Focus on research methods: Levels and applications of qualitative research evidence. Research in Nursing \& Health, 24,145-53.

45. Denison, D.R. (1996). What is the difference between organizational culture and organizational climate? A native's point of view on a decade of paradigm wars. Academy of Management Review, 21(3), 619-54.

46. Brown, J.S., \& Duguid, P. (1991). Organizational learning and communities of practice: Toward a unified view of working, learning and innovation. Organization Science 2(1), 40-57.

47. Smith, D.L. (2001). Facilitating the development of professional craft knowledge. In J. Higgs \& A. Titchen (Eds.), Practice knowledge and expertise in the health professions (pp. 172-177). Oxford: Butterworth Heinemann.

48. Lock, J.V. (2006). A new image: Online communities to facilitate teachers professional development. Journal of Technology and Teacher Education, 14, 663-78.

49. Beach, M.C., \& Inui, T. (2006). Relationship-centered care: A constructive reframing. Journal of General Internal Medicine, 21, S3-S8.

50. Rosenbaum, P., King, S., Law, M., King, G., \& Evans, J. (1998). Family-centred service: A conceptual framework and research review. Physical and Occupational Therapy in Pediatrics, 18(1), 1-20.

51. Ryan-Vincek S, Tuesday-Heathfield, L., Lamorey, S. (1995) From theory to practice: A pilot study of team members' perspectives on transdisciplinary service delivery. Infant-Toddler Intervention, 5(2), 153-76.

52. Borduas, F., Frank, B., Hall, P., Handfield-Jones, R., Hardwick, D., \& Ho, K., et al. (2006). Facilitating the integration of interprofessional education into quality health care: Strategic roles of academic institutions. Health Canada.

53. Martín-Rodríguez, L.S., Beaulieu, M.D., D’Amour, D., Ferrada-Videla, M. (2005). The determinants of successful collaboration: A review of theoretical and empirical studies. Journal of Interprofessional Care, 19, 132-47.

54. Eraut, M. (2006). Feedback. Learning in Health and Social Care, 5, 111-118.

55. Phillips, J.K., Klein, G., \& Sieck, W.R. (2004). Expertise in judgment and decision making: A case for training intuitive decision skills. In D.J. Koehler D.J \& N. Harvey (Eds.), Handbook of judgment and decision making (pp. 297-315). Oxford, UK: Blackwell.

56. Gersten, R., Morvant, M., \& Brengelman, S. (1995). Close to the classroom is close to the bone: Coaching as a means to translate research into classroom practice. Exceptional Children, 62(1), 52-66.

57. Spreitzer, G., Sutcliffe, K., Dutton, J., Sonenshein, S., \& Grant, A.M. (2005). A socially embedded model of thriving at work. Organization Science, 16(5), 537-49.

58. Dornan, T., Boshuizen, H., King, N., \& Scherpbier, A. (2007). Experience-based learning: A model linking the processes and outcomes of medical students' workplace learning. Medical Education, 41, 84-91.

59. Eraut, M. (2003). Professional apprenticeship. Learning in Health and Social Care, 2, 117-22.

60. Eraut, M. (2004). The practice of reflection. Learning in Health and Social Care, 3, 47-52.

61. Warner, H. (2001). Children with additional needs: The transdisciplinary approach. Paediatric Nursing, 13(6), 33-6.

62. D’Amour, D., Ferrada-Videla, M., Rodriguez, L.S.M., \& Beaulieu, M-D. (2005). The conceptual basis for interprofessional collaboration: Core concepts and theoretical frameworks. Journal of Interprofessional Care, 19(2), 116-31.

63. Hargreaves A. (1991). Contrived collegiality: The micropolitics of teacher collaboration. In Blase J., (Ed.)., The politics of life in schools: Power, conflict, and cooperation (pp. 46-72). Newbury Park, CA: Sage.

64. Westling D.L., Cooper-Duffy K., Prohn K., Ray, M., \& Herzog, M.J. (2005). Building a teacher support program. Exceptional Children, 37, 8-13. 